\title{
Mechanical properties of gusset-tube plate joints
}

\author{
Wei Qing Li ${ }^{1, a^{*}}$, Shu Xia Yan ${ }^{1, b}$ \\ ${ }^{1}$ School of Civil Engineering and Architecture, Changzhou Institute of Technology, Changzhou \\ China. \\ agouni@zju.edu.cn, b2494987865@qq.com
}

Keywords: nonlinear; gusset-tube; joint; plastic zone

Abstract. A nonlinear finite element analysis is carried out for the whole process of elastoplastic deformation considering both material and geometry nonlinearity, and the limit states of damage and failure mechanism were studied. According to the analysis, the joints studied show great bearing capacity, which can meet the requirements of the target load and there is a certain security reserve. The results show that the load increased with severe stress concentration at certain parts of the joints. The junction between ring stiffeners, gusset plates and tube walls first come into the plastic stage, and with the increase of load the plastic zone spread out across the entire tube wall which leads to the final failure of the joint.

\section{Introduction}

The joints are the key parts of steel transmission towers. The joints are intersected by various components, which caused very complex stress states, and the stress concentration here is obvious. Experimental study and theoretical analysis have not yet fully developed at home and abroad.

Most of the current research methods are using the finite element method and the stress concentration factor approach to analyze the mechanical properties of this type of steel tube connection[1-5]. Detailed studies on the destruction mechanism of the tube-gusset plate joints have not yet been carried out[6-7]. According to the given analytical methods of the existing codes of many countries, the results are too conservative, hence the designers can not accurately grasp the safety factor of the structure, and it will also affect the economy of constructions adversely[8-12]. At present, there is no specific way to estimate the local buckling of the tube walls and to estimate the difference between stiffened and unstiffened connections. The reference values given by empirical formulas of the codes of foreign countries can not accurately reflect mechanical properties of the joints under different conditions. Therefore, deeper experimental and theoretical research of the ultimate capacity of the tube-gusset plate joints has become a key problem to be solved.

Based on the project of a long-span tall transmission tower, researches about the mechanical properties of K-shaped tube-gusset plate joints were carried out.
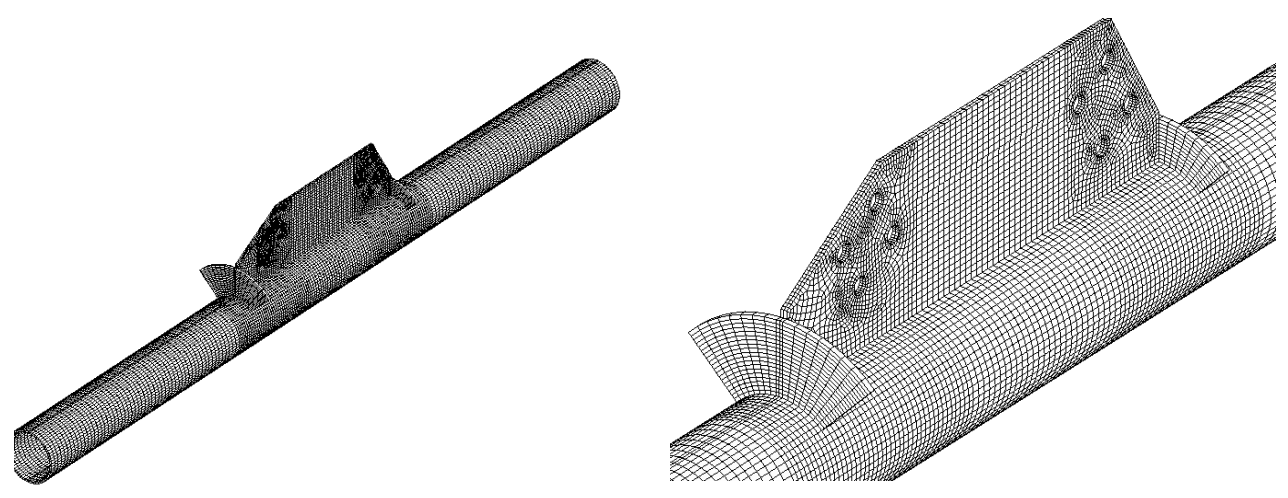

Fig. 1. Finite element model. 


\section{Finite element model}

Fig. 1 shows the Finite element model of the ring stiffened gusset-tube joints. In the numerical analysis of the joints, in order to better analyze the stress distribution 8 nodes (each node with three degrees of freedom) hexahedral solid elements Solid185 is used. The constraints and loads of the FEA specimens are applied according to the actual conditions. For the steel tubular tower joint, one end of the main tube is considered as the fixed bearing, and the other end is the directional support with the axial displacement of the main tube. Q345 steel, elastic modulus and Poisson's ratio of 0.3 are used in this paper. The elastic-plastic development of the material is determined by the von Mises yield criterion.

\section{Expansion of plastic zone}

According to the finite element calculation results the plastic deformations are observed mainly in three areas: the junctions, the two sides of the gusset plate and both ends of the stiffening plate. At both ends of the stiffening plate, the plastic zone expands gradually with the increase of load, until the plastic zone spread out through the whole main tube. The final failure occurs at the ends on both sides of the gusset.
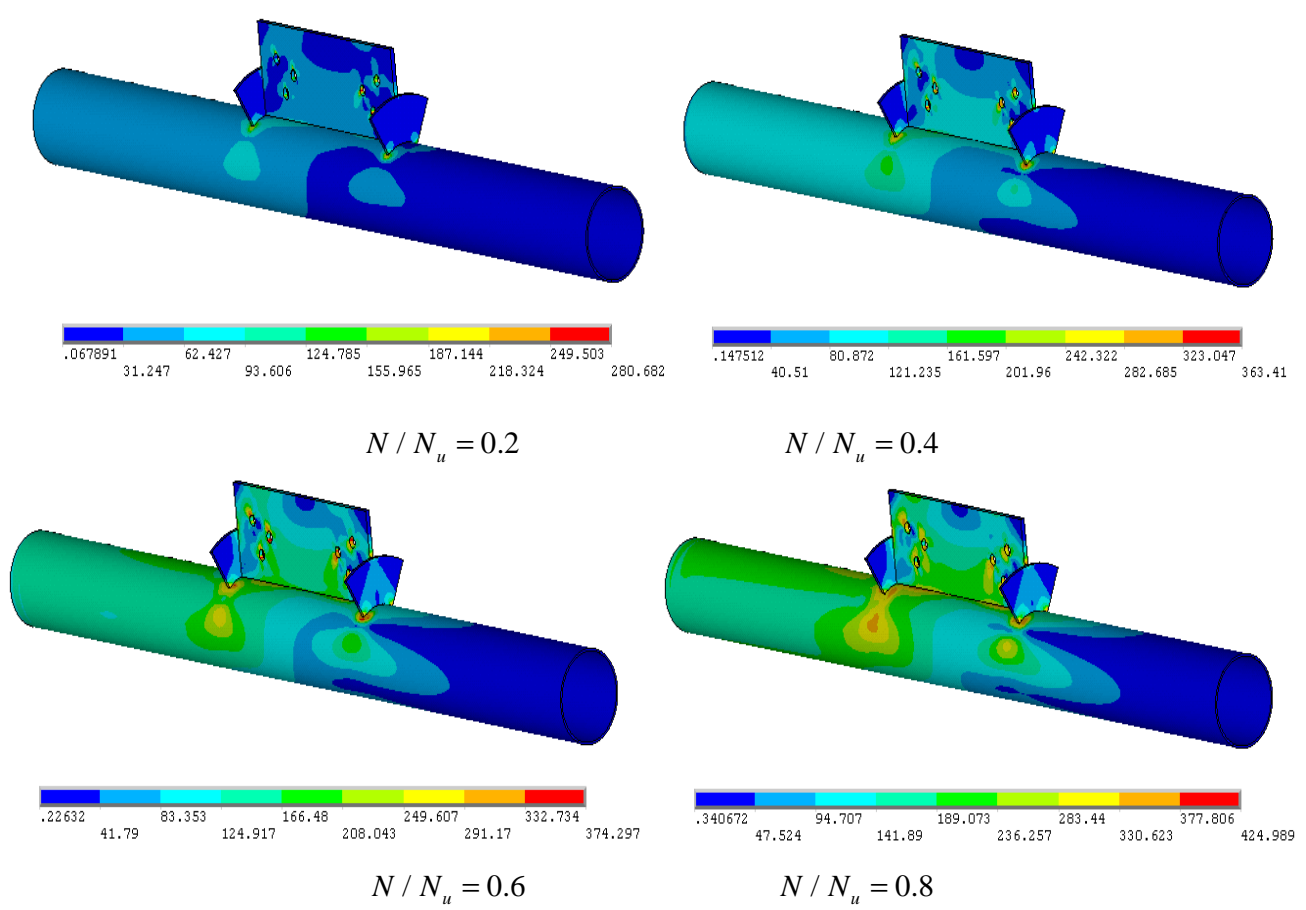

$N / N_{u}=0.8$
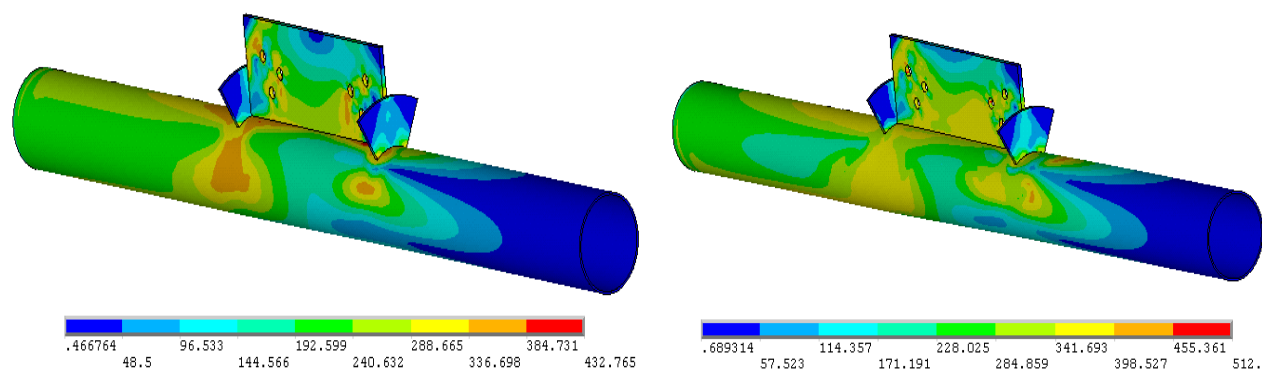

$$
N / N_{u}=1
$$

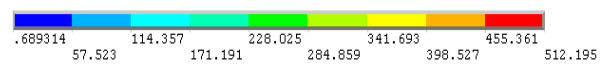

$N / N_{u}=1.18$

Fig. 2. Distribution of plastic zone

Failure mode 1: excessive plastic deformation of the tube wall in the tension side. The main reason of this phenomenon is that the width of the stiffened plate and its stiffness are relatively large, and the tube has been stretched from the ends of the stiffening plate the plastic zone begins to expand downward until the bottom of the main tube. 
Failure mode 2: over plastic deformation of the tube wall in the compression side. The main reason of this phenomenon is that the width of the stiffened plate is small.

\section{Mechanical properties}

Distribution and development of the stress and strain in different parts of the joints, such as the junction between the gusset plate and the tube, the interfacing region between the main tube and the ring stiffening, and the interfacing region between the gusset plate and the ring stiffening are studied.

The stress of the tube wall near the location of the tension zone where $\mathrm{z}=100 \mathrm{~mm}$ is the largest. Due to the stress distribution in this region, the stress is uniformly distributed, and the maximum stress is $350 \mathrm{MPa}$. The maximum stress in the compression zone is located near $\mathrm{z}=480 \mathrm{~mm}$. Along with the increase of load level, stress grow rapidly in the tension zone, the growth of the stress in the compression zone is also accelerated. The stress distribution in the middle part of the joint is relatively flat, and its value always in the elastic stage during the whole loading process. The stress of the tube wall in the compression zone is smaller than that of the tension zone. The minimum stress distribution area is located near the end of the compression zone, i.e., $\mathrm{z}=600 \mathrm{~mm}$. the neutral axis moves gradually toward the right side of the gusset plate, which means that under the interaction of the moment and shear force the position of the neutral axial will change instead of fixing in the midpoint of the gusset as conventional assumption.
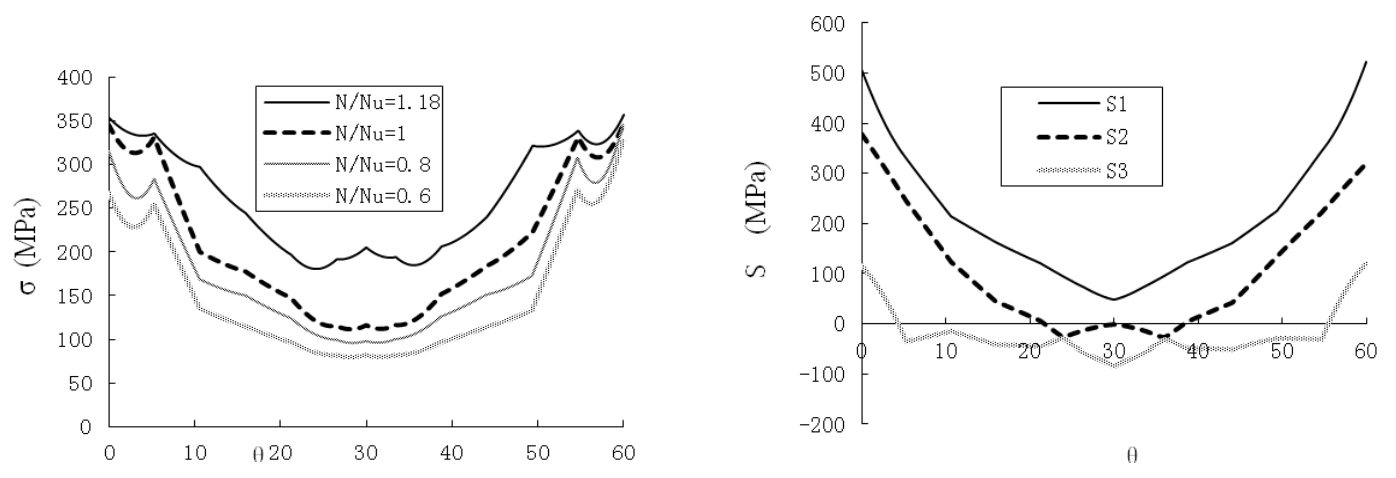

Fig. 3. Mises stresses and principle stresses distribution of the ring stiffener

Fig. 3 shows the Mises stress and principle stress distribution of the ring stiffener. It can be seen that the stress value at the junction of the stiffening plate and the main tube is the biggest, certain parts have been entered into the plastic stage, other parts are still in elastic state.

Fig. 4 is the stress distribution of stiffeners. From the graph, we can see that in the region near the maximum principal tensile stress and the main compressive stress, the region is mainly subjected to tension and compression deformation, and the shear deformation mainly occurs in the area far away from the maximum principal tension or compressive stress. The principle compressive stress value of the ring stiffener is very small. Maximum tensile stress appears at the junction of the two toes of the stiffener.
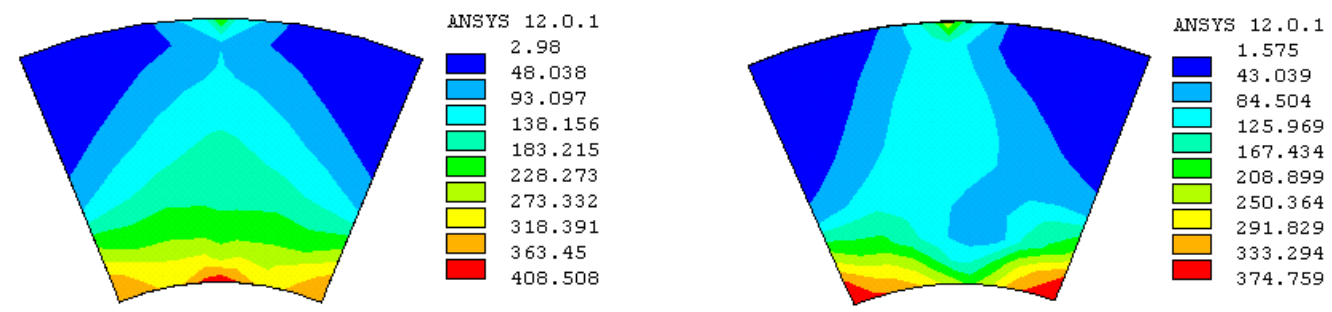

Fig. 4. Stress distribution of stiffeners 


\section{Summary}

The interface between the main tube and the gusset plate is the most dangerous region of the whole joint. Severe stress concentration occurs around this region, and the final damage is cause by the wide spread of plasticity across the main tube.

1. There are three stages from the beginning of loading to the final destruction. According to the finite element calculation results the plastic deformations are observed mainly in three areas: the junctions, the two sides of the gusset plate and both ends of the stiffening plate. At both ends of the stiffening plate, the plastic zone expands gradually with the increase of load, until the plastic zone spread out through the whole main tube. The final failure occurs at the ends on both sides of the gusset.

2. The gusset-tube joints have strong plastic deformation capacity and high strength reserve. The bearing capacities greatly enhance when the joints are stiffened by ring stiffeners.

3. The length of the junction region between the main tube and ring stiffener should be enough long to ensure that there will not be too severe stress concentration.

\section{Acknowledgements}

This research project was supported by the scientific research project of Ministry of Housing and Urban-rural (project number: 2013-K2-23).

\section{References}

[1] Packer JA, Henderson JE. Design guide for hollow structural section connections[S]. Canadian Inst Steel.

[2] STELCO, 1971, Hollow structural sections-design manual for connections, 1st. ed., Stelco Inc., Hamilton, Ontario.

[3] Mitri H S.Ultimate in-plane moment capacity of T and Y tubular joints.Journal of Constructional Steel Research.1989, 12:69-80.

[4] Marshall P W.Designing tubular connections with AWS D1.1.Welding [J]. Journal. 1989, 68(3):45-52.

[5] Lee Young-Shin, Kim Young-Wann, Nonlinear free vibration analysis of rotating hybrid cylindrical shells [J]. Computer and Structures, 1999, 70: 161-168.

[6] Lee M M K, Wilmshrust S R. Numerical modelling of CHS joints with multiplanar double-K configuration[J]. Journal of Constructional Steel deferrer Research.1995, 32:281-301.

[7] Chan T K,Soh C K,Fung T C.Experimental study of a full-scale multiplanar tubular XT-joint. In:Choo Y S,van der Vegte G J,eds. Proceedings of the Eighth International Symposium on Tubular Structures. Singapore:1998.131-138.

[8] Scola S,Redwood R G, Mitri H S. Behaviour of axially loaded tubular V-joints[J]. Journal of Constructional Steel Research. 1990, 16: 89-109.

[9] Kosteski N,Packer J A.Experimental examination of branch plate-to-RHS member connection types.In:Puthli R,Herion S,eds. Proceedings of the Ninth International Symposium on Tubular Structures. Dusseldorf: 2001.135-144.

[10] Wang B,Hu N,Kurobane $\mathrm{Y}$ et al.Damage criterion and safety assessment approach to Tubular joints. Engineering Structures. 2000, 22:424-434.

[11] Kosteski N,Packer J A.FEM evaluation of stiffened longitudinal branch Plate-to-RHS member connections. In: Puthli R, Herion S, eds. Proceedings of the Ninth International Symposium on Tubular Structures.Dusseldorf:2001.145-154. 
[12] Cao J J,Packer J A,Kosteski N.Parametric finite element study of connections between longitudinal plates and RHS columns.In: Choo Y S, van der Vegte G J, eds.Proceedings of the Eighth International Symposium on Tubular Structures. Singapore: 1998.645-654. 